\title{
Uso de geotecnologia na análise de conforto térmico e áreas de APP em um perímetro urbano
}

\author{
Use of geotechnology in the thermal comfort analysis and APP areas of an urban \\ perimeter
}

Uso de geotecnología en el análisis de confort térmico y áreas de APP en un perímetro urbano

Lais Fernanda Silva Menezes

Engenheira agrícola, UFMT, Brasil.

Cássia Maria Bonifácio

Doutoranda, UEM, Brasil. cassiabonifacio@hotmail.com

André Marcondes Andrade Toledo

Professor Doutor, UFSCar, Brasil. amatoledo@gmail.com 


\section{RESUMO}

No cenário de expansão urbana a relação homem/natureza é um fator preocupante para as questões ambientais. 0 uso de geotecnologias pode se tornar uma ferramenta valiosa para os gestores e planejadores, visando proporcionar uma melhor qualidade de vida à população. Esta pesquisa teve como objetivo geral realizar uma análise ambiental e do conforto térmico do perímetro urbano de Rondonópolis-MT, com o uso de geotecnologias para avaliar a distribuição espacial de temperatura e umidade relativa do ar e áreas de preservação permanente. A delimitação para a análise da área de preservação se deu de forma visual através de uma imagem Quickbird e quantificada para posterior diagnóstico. Foram coletados também dados de temperatura e umidade relativa do ar e com esses registros realizados interpolação para gerar carta-imagens. Por meio dos mapas de temperaturas e umidade relativas do ar foi possível constatar que o maior "stress" térmico foi apresentado no Centro da cidade, os maiores índices de conforto térmico foram observados na direção leste e nordeste, onde se localizam os pontos do Jardim Atlântico e Jardim das Flores, respectivamente. Já com o diagnóstico das áreas de preservação permanente do perímetro urbano, foi possível observar que os rios e córregos apresentam situação irregular em toda sua extensão.

PALAVRAS-CHAVE: Geoprocessamento. Conforto térmico. Análise ambiental.

\section{RESUMEN}

En el escenario de expansión urbana la relación hombre/naturaleza es un factor preocupante para las cuestiones ambientales. El uso de geotecnologías puede convertirse en una herramienta valiosa para los gestores y planificadores, con el fin de proporcionar una mejor calidad de vida a la población. Esta investigación tuvo como objetivo general realizar un análisis ambiental y del confort térmico del perímetro urbano de Rondonópolis-MT, con el uso de geotecnologías para evaluar la distribución espacial de temperatura y humedad relativa del aire y áreas de preservación permanente. La delimitación para el análisis del área de preservación se dio de forma visual a través de una imagen Quickbird y fue cuantificada para posterior diagnóstico. Se recogieron también datos de temperatura y humedad relativa del aire y con esos registros se han realizado la interpolación para generar cartaimágenes. A través de los mapas de temperaturas y humedad relativa del aire fue posible constatar que el mayor "stress" térmico fue presentado en el Centro de la ciudad, los mayores índices de confort térmico se observaron en la dirección este y nordeste, donde se localizan los puntos del Jardim Atlântico y Jardim das Flores, respectivamente. Con el diagnóstico de las áreas de preservación permanente del perímetro urbano, fue posible observar que los ríos y arroyos presentan situación irregular en toda su extensión.

PALABRAS CLAVE: Geoprocesamiento. Confort térmico. Análisis ambiental.

\section{ABSTRACT}

In the scenario of urban expansion the relation man/nature is a worrying factor for environmental issues. The use of geotechnology can become a valuable tool for managers and planners, aiming to provide a better quality of life for the population. This research had as general objective to perform an environmental analysis and the thermal comfort of the urban perimeter of Rondonópolis-MT, with the use of geotechnologies to evaluate the spatial distribution of temperature and relative humidity of the air and permanent preservation areas. The delimitation for the analysis of the preservation area was done visually through a Quickbird image and quantified for later diagnosis. Data were also collected from temperature and relative humidity of the air and with these records performed interpolation to generate letter-images. Through the maps of relative temperatures and humidity of the air it was possible to verify that the greatest thermal stress was presented in the city center, the highest thermal comfort indexes were observed in the east and northeast direction, where the points of the Jardim Atlântico and Jardim das Flores, respectively. Already with the diagnosis of the areas of permanent preservation of the urban perimeter, it was possible to observe that the rivers and streams present irregular situation in all their extension.

KEY WORDS: Geoprocessing. Thermal comfort. Environmental analysis. 


\section{INTRODUÇÃO}

A questão ambiental é muito discutida no mundo contemporâneo e, sua análise e compreensão requer ponderação sobre os valores e ideais humanos adotados até o momento, sobretudo no que diz respeito à relação homem/natureza, que atualmente é uma das maiores preocupações dos planejadores e gestores ambientais (FLORÊNCIO \& QUEIROZ, 2011).

O conceito de qualidade ambiental integra um conceito maior definido como qualidade de vida. Este, por sua vez, é um diagnóstico da existência ou não de condições saudáveis de habitação, em termos humanos, sociais, ecológico-ambientais, econômicos, dentre outros, obtidos em conjunto num determinado local (MINAKI \& AMORIM, 2006).

Com o crescimento demográfico observa-se uma proliferação de resíduos que contaminam o ambiente e afetam os ecossistemas. Neste cenário, uma variável a ser considerada é a expansão urbana, que em muitos casos ocorre de forma desordenada por falta de planejamento territorial. Esse problema altera os padrões de acessibilidade intra-urbana das cidades médias brasileiras, como é o caso de Rondonópolis, cidade situada no Sudeste do Estado de Mato Grosso, conhecida pelo potencial agropecuário e que vem apresentando expressivo crescimento dos setores industrial e comercial na primeira década deste século. A função desse planejamento é justamente fazer com que as transformações no meio ambiente ocorram de modo equilibrado, lembrando que atualmente o gerenciamento da qualidade ambiental nas cidades tem-se voltado, prioritariamente, para problemas de poluição do ar, ruído, disponibilidade de água, poluição visual, condições precárias de habitação, depósitos de lixo e outros. Somam-se, a estes aspectos, os problemas decorrentes da indução de processos do meio físico, cujas consequências agravam as condições de saúde, segurança, e a qualidade de vida nas cidades (RAUBER, 2008).

Os processos que ocorrem no meio físico estão ligados à perda de qualidade ambiental nas áreas urbanas e, são possíveis de observar por meio de estudos, como a migração de espécies de animais para outras áreas ou sua extinção; a impermeabilização excessiva do solo (causa de enchentes, erosão e assoreamento de mananciais); a alteração do microclima (com possível impacto sobre as condições térmicas da cidade); dentre outros explicam que a manutenção de áreas verdes e uma gestão adequada é, portanto, crucial para a qualidade de vida urbana (LOBODA \& ANGELLIS, 2005).

Neste sentido, este estudo teve como objetivo geral realizar a análise ambiental e conforto térmico do perímetro urbano de Rondonópolis-MT, com uso de geotecnologias, tomando-se como base a expansão urbana, as áreas de preservação permanente na rede de drenagem, conforme a legislação vigente, e a distribuição espacial da temperatura e umidade relativa do ar, para apoio às tomadas de decisões de agentes envolvidos. 


\section{A relação temperatura e umidade relativa do ar no clima urbano}

No estudo sobre o clima urbano Lima (2006) destaca que a substituição dos ambientes naturais por áreas urbanas provoca o aumento das temperaturas nas escalas locais, e que, este fenômeno ocorre em função de vários fatores, como: a diminuição das áreas verdes, a canalização dos córregos, o aumento das indústrias que liberam poluentes na atmosfera entre outras atividades inerentes à vida nas cidades, que além de gerarem o aumento nas temperaturas, causam a redução da umidade relativa do ar originando um clima partícula clima urbano.

Sobre a Teoria e Clima urbano,

a) o clima urbano é a modificação substancial de um clima local, não sendo possível ainda decidir sobre o ponto de concentração populacional ou densidade de edificações em que essa notável mudança principia;

b) admite-se que o desenvolvimento urbano tende a acentuar ou eliminar as diferenças causadas pela posição do sítio;

c) da comparação entre a cidade e o circundante, emergiram os seguintes fatos fundamentais: 1) a cidade modifica o clima através de alterações em superfície; 2) a cidade produz aumento de calor, complementada por modificações na ventilação, na umidade e até nas precipitações que tendem a ser mais acentuadas; [...]. (LANDSBERG apud MONTEIRO, 1976, p. 57).

A redução de áreas verdes tem seus efeitos, como o decréscimo da evapotranspiração pela impermeabilização das superfícies urbanas e redução de áreas verdes nas cidades. A reduzida fração de área vegetada em áreas fortemente urbanizadas diminui a extensão das superfícies de evaporação (lagos, rios) e de evapotranspiração (parques, bosques, jardins, bulevares). Assim, as atividades humanas alteram os microclimas urbanos e as condições de conforto ambiental das cidades. A impermeabilização dos solos devido à pavimentação e desvio da água por bueiro e galerias, o que reduz o processo de evaporação e evapotranspiração urbana, modificando o balanço hídrico da superfície urbana podendo aumentar a vulnerabilidade da população a enchentes e deslizamentos de terra (LOMBARDO, 1985).

\section{Sistemas de informações geográficas: geotecnologias}

Barcellos e Bastos (1996) explicam que fatores culturais, econômicos, demográficos e ambientais estão presentes em todas as grandezas em que se represente o espaço. As variáveis culturais apresentam os maiores diferenciais, e estão presentes na escala nacional, regional e local com menor intensidade. A variável renda possui fortes diferenciais em todas as grandezas possíveis de análise, pois segundo os autores, serve para distinguir conjuntos de países, da mesma forma que conjuntos de bairros. 
Sendo assim, o conceito de geotecnologia abrange a aquisição, armazenamento, processamento, análise e integração de informações espacialmente referenciadas. É considerado um grupo de tecnologias de informação geograficamente referenciada, dentre as quais pode-se citar o GPS, SIG, fotogrametria, levantamentos aéreos ou orbitais, topografia, cartografia, geodésia, dentre outras (FITZ, 2009).

O geoprocessamento permite a construção e operação de bases cartográficas em diversas escalas, a estrutura e inter-relacionamento dos bancos de dados fixam um modelo de agregação de dados por unidade espacial. Desse modo, ao se definir o objeto de estudo, elegese uma escala de análise que deve ser compatível com o fenômeno sobre o qual se deseja trabalhar.

Conforme esclarece Piquet et. al (1986, apud Barcellos e Bastos, 1996), a homogeneidade interna da unidade espacial depende basicamente dos critérios e variáveis utilizados na concepção do sistema. Uma importante mudança de ponto de vista se dá entre atividades de planejamento e análise, que se utilizam do espaço como categoria de trabalho.

Barcellos e Bastos (1996) argumentam que no caso do geoprocessamento, a escolha da escala de trabalho se delineia com o estabelecimento a priori das unidades de agregação de dados e da extensão do território de trabalho. Por exemplo, ao se trabalhar com os municípios do Brasil (numa escala de 1:1.000.000) as cidades podem ser representadas por pontos. Neste caso, as diferenciações internas às cidades desaparecem e opta-se por analisar as relações entre cidades. Esta escolha terá consequências importantes sobre os processos que se pretende estudar espacialmente. Além de restringir sua abrangência, a escala de análise condiciona os estudos em saúde ambiental, fornecendo maior ou menor peso a fatores sociais, ambientais e econômicos.

Os autores supracitados explicam que bairros, cidades e países possuem organizações internas diferentes, o que conduz a análise para campos do conhecimento que melhor as expliquem. Desta maneira, as respostas a questões acerca dos padrões de distribuição espacial de agravos à saúde podem variar de acordo com a escala adotada. E, dentre as variáveis ambientais, os fenômenos climáticos possuem maiores gradientes espaciais em escalas regionais ou globais. O estudo dos efeitos da redução da camada de ozônio sobre a saúde deve ser desenvolvido nesta escala, já que os danos à camada de ozônio têm as dimensões de um país. Por outro lado, é no nível local onde melhor se verificam fatores ligados à poluição atmosférica, uma vez que a difusão atmosférica de poluentes pode alcançar alguns quilômetros (BARCELLOS e Bastos, 1996).

\section{MÉTODOS}

A área de estudo compreende o perímetro urbano da cidade de Rondonópolis, localizada na região Sudeste do Estado de Mato Grosso. O Centro da cidade se localiza no ponto com as coordenadas $16^{\circ} 28^{\prime} 15.31^{\prime \prime}$ S e $54^{\circ} 38^{\prime} 03.05^{\prime \prime}$ (Figura 1). 
Figura 1: Mapa representando parte do perímetro urbano do município de Rondonópolis-MT.

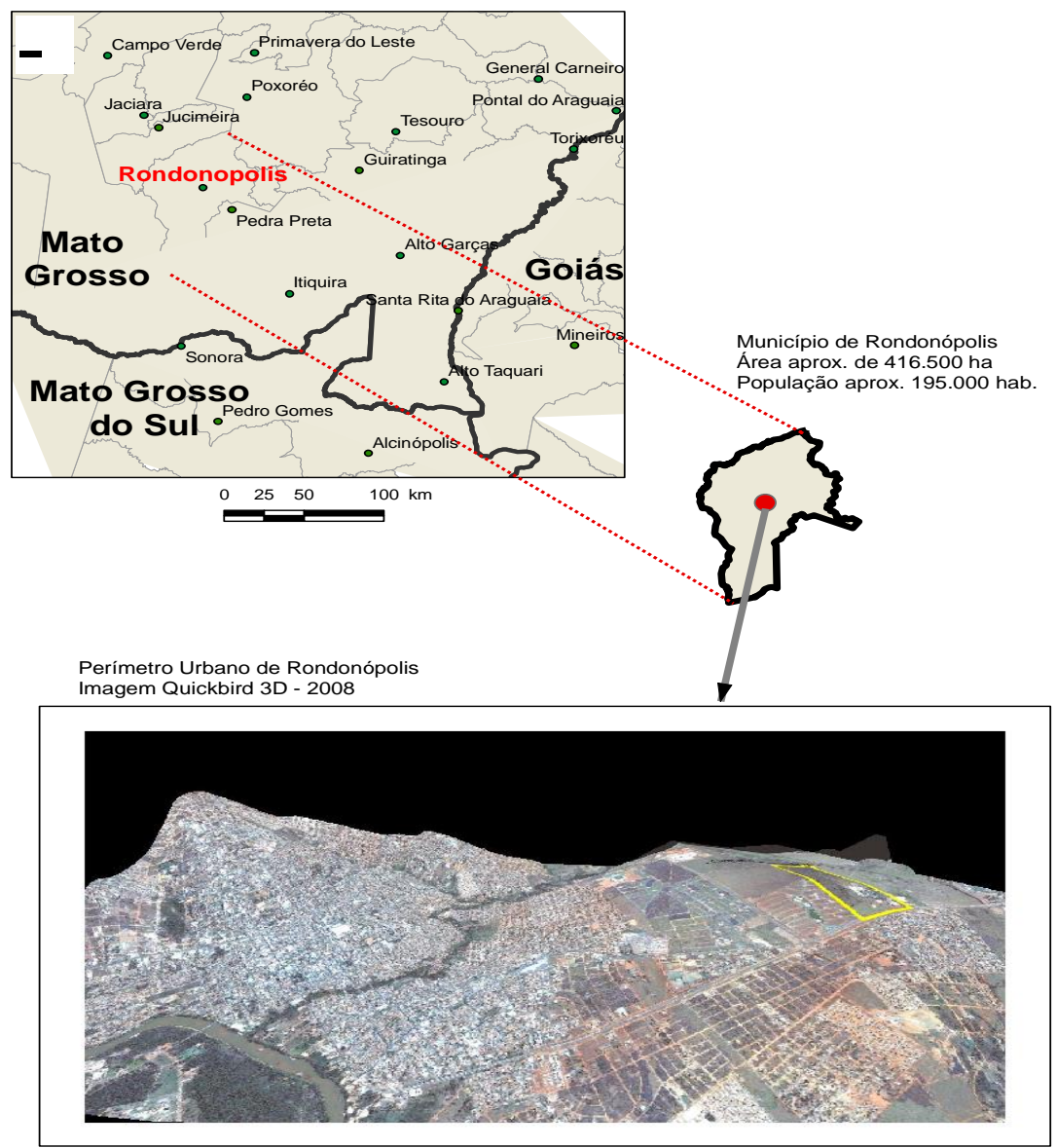

Fonte: PROEXT MCidades/UFMT.

Levantamento e processamento dos dados de temperatura e umidade relativa do ar

A primeira etapa de levantamento consistiu na organização do trabalho de campo, com observações e registros das temperaturas e umidades relativas do ar no perímetro urbano do município. O critério de escolha dos pontos foi à localização dos bairros, de modo que os pontos ficassem bem distribuídos na zona urbana da cidade.

As temperaturas e umidades relativas do ar foram coletadas nos bairros Jardim Atlântico, Jardim Brasília, Jardim Pindorama, Monte Líbano, Conjunto São José III, Jardim das Flores, Cais do Porto e no Centro da cidade.

Para coleta dos dados de temperatura e umidade foi utilizado um termo higrômetro, de marca Incoterm, onde a temperatura é dada em graus Celsius e a umidade relativa do ar é obtida em porcentagem.

Os dados de temperaturas e umidades relativas do ar foram coletados semanalmente, em um período de quatro meses, em três horários distintos, as sete (7:00h), quatorze (14:00h) e vinte e uma horas (21:00h). Os horários foram escolhidos baseados no cálculo da temperatura média do ar, do Instituto Agronômico de Campinas, com estudo realizado por Sentelhas e Angelocci (2009) sobre temperatura do solo e do ar. Os dados obtidos no período foram 
organizados em planilha eletrônica e realizadas as médias de temperatura e umidade relativa do ar dos três horários de coleta.

Os cálculos das médias de temperatura total foram realizados conforme metodologia apresentada por Sentelhas e Angelocci (2009), da seguinte forma:

$$
\begin{aligned}
& \text { Tmed }=(\mathrm{T} 7 \mathrm{~h}+\mathrm{T} 14 \mathrm{~h}+(2 * \mathrm{~T} 21 \mathrm{~h})) / 4 \\
& \text { Onde, } \\
& \mathrm{Tmed}=\text { temperatura média } \\
& \mathrm{T} 7 \mathrm{~h}=\text { temperatura às } 7: 00 \mathrm{~h} \\
& \mathrm{~T} 14 \mathrm{~h}=\text { temperatura às } 14: 00 \mathrm{~h} \\
& \mathrm{~T} 21 \mathrm{~h}=\text { temperatura às } 21: 00 \mathrm{~h}
\end{aligned}
$$

As coordenadas dos pontos selecionados foram obtidas através de um GPS (Sistema de Posicionamento Global), marca Garmim, modelo Legend H. Posteriormente esses dados do GPS foram descarregados no software TrackMaker para o download dos pontos e posterior visualização dos pontos sobre imagem de satélite do município, propiciadas pelo software Google Earth.

A seguir são apresentadas algumas observações levantadas dos locais de coleta de dados, de temperatura e umidade relativa do ar, considerados neste estudo. Os oito pontos de coletas foram:

I. Jardim Atlântico - a $284 \mathrm{~m}$ de elevação, localizado em uma área densamente construída, mas com presença de vegetação arbórea, e com baixo fluxo de veículos.

II. Jardim Brasília - a $216 \mathrm{~m}$ de elevação, localizado em área com alta densidade de construção, com vegetação arbórea, ponto próximo ao Ribeirão Arareau.

III. Jardim Pindorama - a $262 \mathrm{~m}$ de elevação, densidade alta de construções, presença de arborização, baixo fluxo de veículos.

IV. Monte Líbano - a 300m de elevação, densidade de construções e arborização esparsas, com pouco fluxo de veículos.

V. Conjunto São José III - a 289 m de elevação, conjunto habitacional densamente construído, com vegetação esparsa nas ruas e fundos de quintal.

VI. Jardim das Flores - a 260m de elevação, bairro com menor densidade de construções, maior parte da vegetação em fundos de quintais.

VII. Cais do Porto - a $212 \mathrm{~m}$ de elevação, local com fluxo de veículos elevado, com densidade de construções considerável, mas com presença de vegetação arbórea.

VIII. Centro - a $226 \mathrm{~m}$ de elevação, local com elevado fluxo de veículos, maior taxa de impermeabilização, alta densidade de edificações, com pouca presença de vegetação arbórea. A espacialização dos pontos de coleta de temperatura e umidade relativa do ar no perímetro urbano de Rondonópolis-MT pode ser observada na Figura 2. 
Nesse processo foi utilizado o software ArcGIS 9.3.1, criando um arquivo vetorial em extensão shapefile (.shp) para cada curso d'água supracitado. $O$ arquivo vetorial criado foi colocado na mesma projeção da imagem Quickbird e foi escolhida a opção polígonos, para delimitação da mata ciliar. Em seguida, iniciou-se o processo de vetorização pelo método de interpretação visual.

Após a delimitação da mata ciliar, o plano de informação foi processado no software Terraview 3.3.1 para realizar o diagnóstico nas áreas de preservação permanente (APPs) da área sob estudo. Nesse processo, baseado na hidrografia urbana, foi realizado a criação de buffers correspondentes às APPs utilizando a ferramenta "operações geográficas".

Depois da criação dos buffers utilizou-se a operação geográfica "diferença", subtraindo a quantidade de mata ciliar em relação às APPs para identificação de situação irregular nessas áreas de preservação.

\section{RESULTADOS}

\section{Temperatura e umidade relativa do ar}

Após realizar a coleta dos dados, efetuar o cálculo de média total, proceder a interpolação e elaborar as carta-imagens com a distribuição espacial de temperatura e umidade do ar, constatou-se que no período analisado a variação de temperatura no perímetro urbano de Rondonópolis é de $4{ }^{\circ} \mathrm{C}$ enquanto a umidade do ar é de 4,8 pontos percentuais, conforme pode ser observado, respectivamente, nas Figuras 3 e 4 .

A temperatura média variou de $26^{\circ} \mathrm{C}$ a $30{ }^{\circ} \mathrm{C}$, sendo os valores mais elevados de temperatura registrados no Centro de Rondonópolis e os mais baixos no setor leste da cidade, região do bairro Atlântico. A média de umidade relativa do ar variou de $45,4 \%$ a $50,2 \%$, sendo os menores valores registrados no Centro e os mais elevados no setor leste. Portanto, constata-se que regiões no perímetro urbano com as temperaturas mais elevadas apresentam menores valores de umidade relativa do ar. 


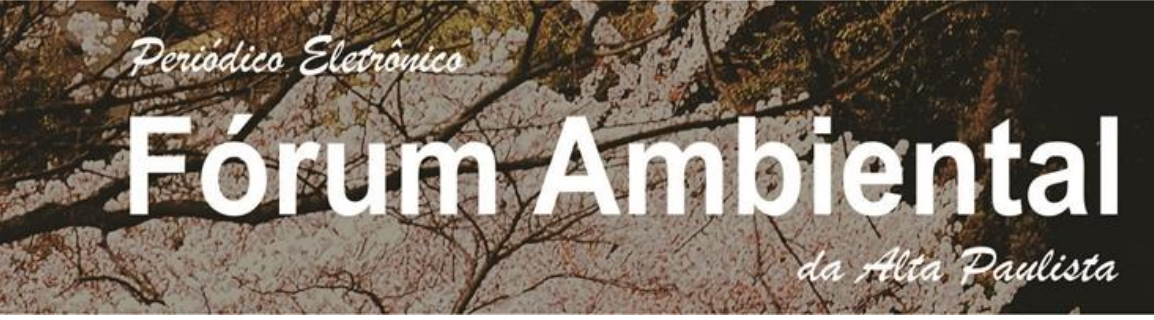

Figura 3: Carta-imagem do perímetro urbano de Rondonópolis representando as médias de temperatura total.

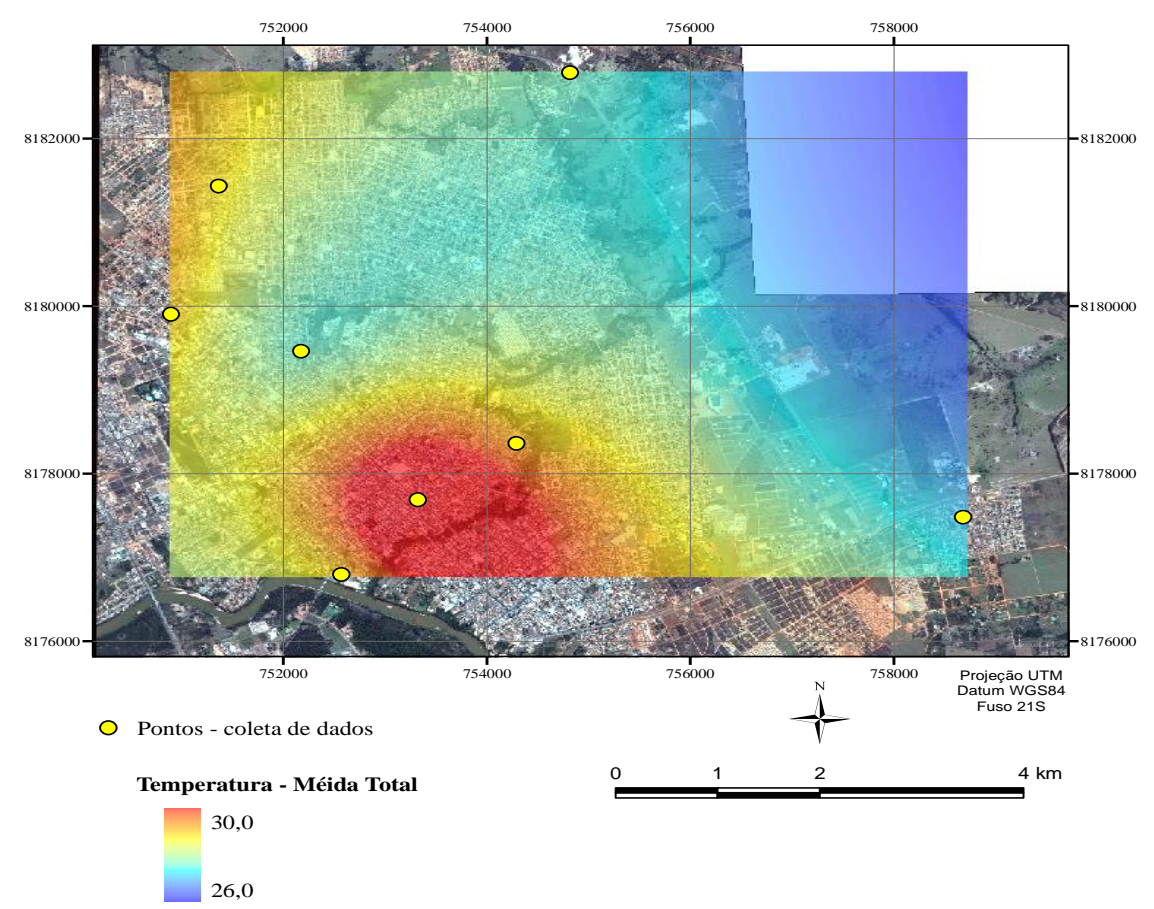

Figura 4: Carta-imagem do perímetro urbano de Rondonópolis representando a média de umidade relativa do ar total.

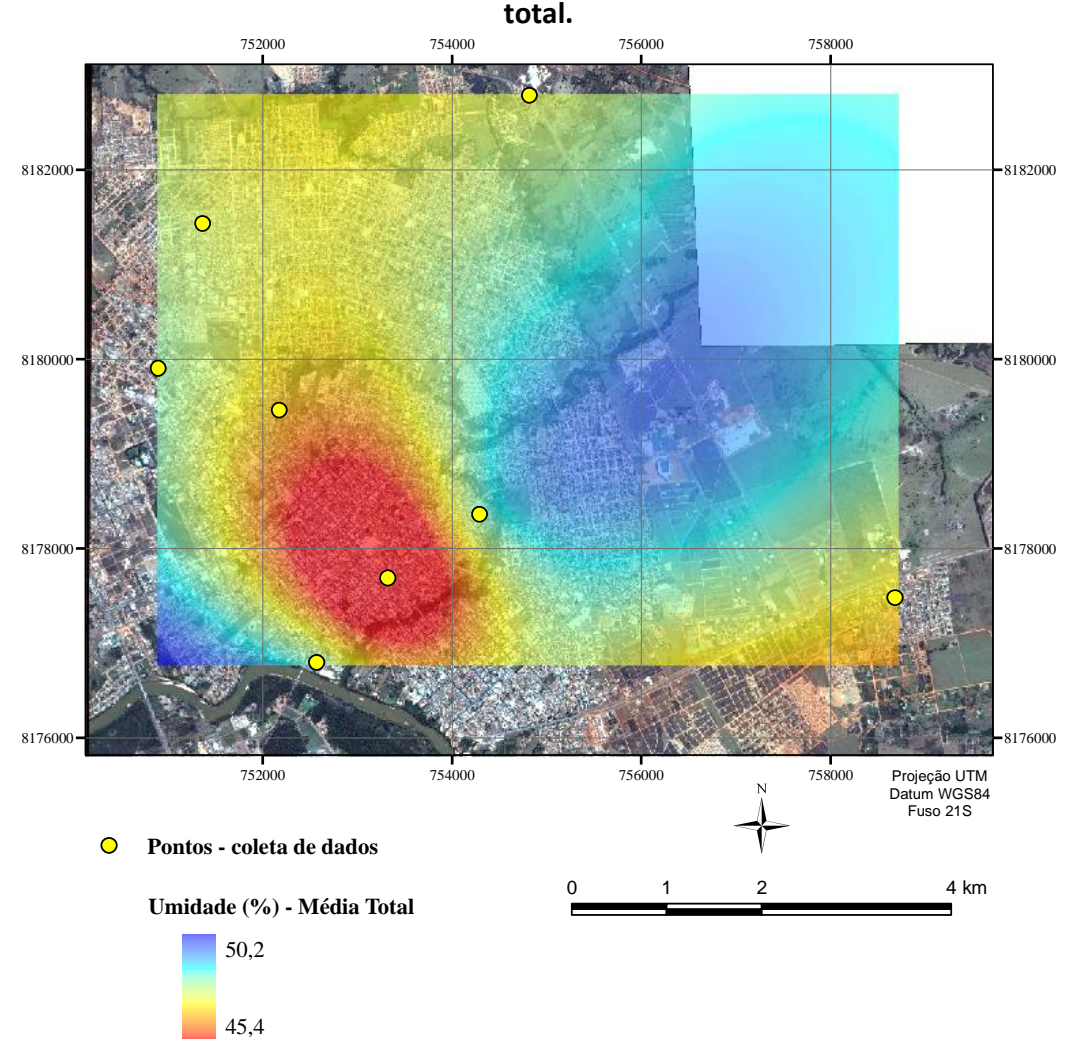

Nos mapas representando a média das coletas realizadas às 7 horas (Figura 5), observa-se que a variação térmica foi de $5,4{ }^{\circ} \mathrm{C}$, de 22,2 a $27,6{ }^{\circ} \mathrm{C}$, sendo as temperaturas mais baixas 
registradas no bairro Jardim Atlântico e as mais elevadas no Centro da cidade. Com relação à umidade do ar a variação foi de 8,2 pontos percentuais nas coletas realizadas às 7 horas, variando de 47 a 55,2 pontos percentuais, com valores mais baixos registrados no Centro e os mais altos no Jardim Atlântico. A maior variação observada neste horário, comparado à média total, possivelmente está relacionado ao resfriamento mais rápido do ar durante o período noturno na região leste, região do bairro Atlântico, na qual a altitude é cerca de 80 metros mais elevada que o centro da cidade e também pelo fato de possuir mais área verde.

Figura 5: Carta-imagem do perímetro urbano de Rondonópolis representando a média de temperatura e umidade relativa do ar às 7 horas.

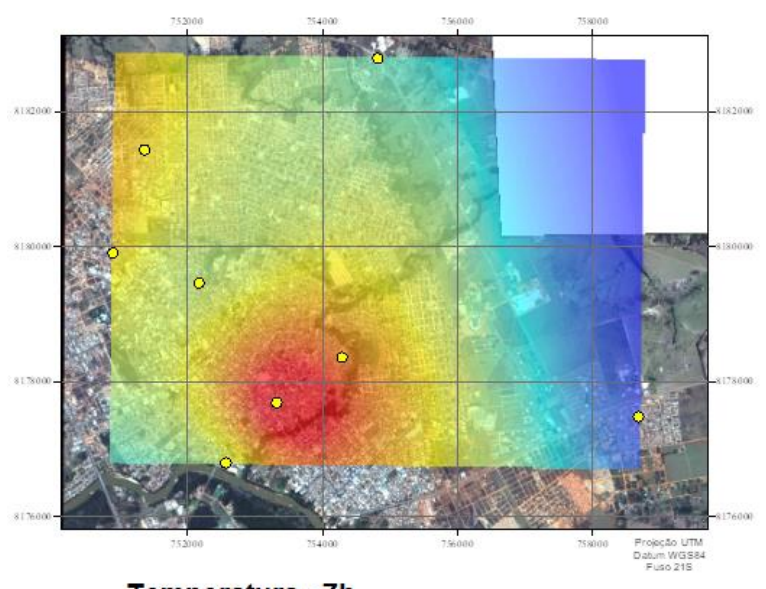

Temperatura $-7 \mathrm{~h}$

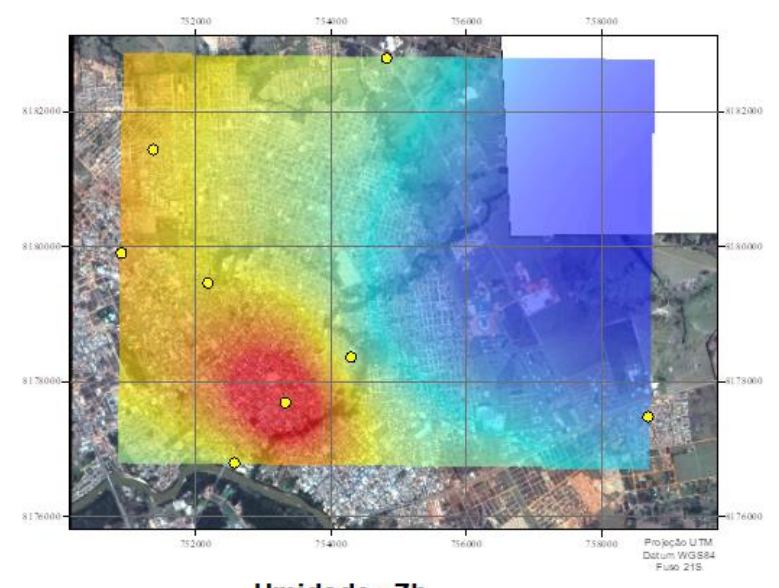

Umidade $-7 \mathrm{~h}$

Com relação às coletas realizadas às 14 horas, observa-se na Figura 6, respectivamente, a distribuição espacial de temperatura e umidade relativa do ar, nas quais constata-se que a variação de temperatura foi de $3{ }^{\circ} \mathrm{C}$, variando de 29,9 a $32,9^{\circ} \mathrm{C}$ enquanto de umidade foi de 5,8 pontos percentuais, de 40,2 a 46 pontos. Os valores de temperatura mais elevados foram registrados no Centro da cidade e os mais baixos na região do bairro Jardim das Flores. Os valores mais elevados de umidade do ar, próximo de 46 pontos percentuais, ocorreram no entorno do ponto de coleta localizado no bairro Monte Líbano enquanto os mais baixos no bairro Jardim Atlântico (40\%). 
Figura 6: Carta-imagem do perímetro urbano de Rondonópolis representando a média de temperatura e umidade relativa do ar às 14 horas.

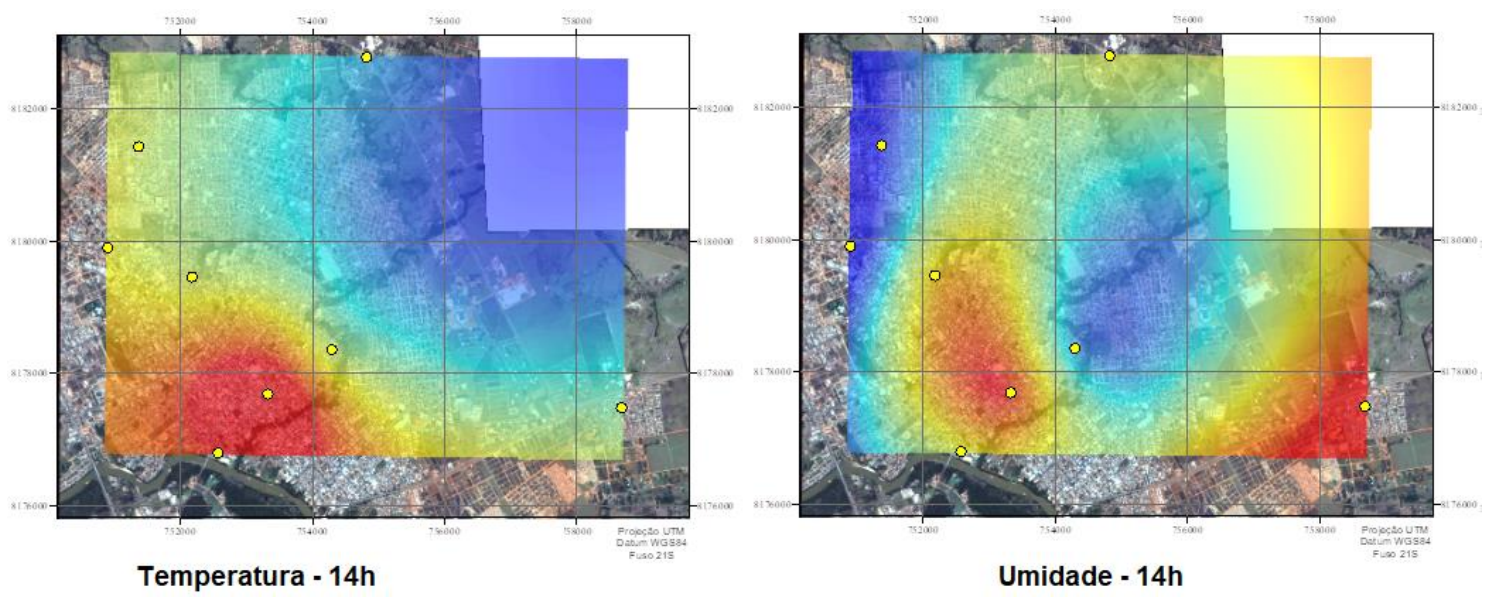

A distribuição espacial dos valores médios de temperatura, correspondente às coletas realizadas às 21 horas, pode ser observada na Figura 7, na qual se constata que a variação de temperatura é de $3,9^{\circ} \mathrm{C}$, variando de $25,9^{\circ} \mathrm{C}$, correspondente ao entorno do ponto Jardim Pindorama e à porção leste do perímetro urbano, até $29,8^{\circ} \mathrm{C}$, correspondente ao centro da cidade. Com relação à umidade do ar, observa-se na figura 10 que a amplitude foi 6,4 pontos percentuais, variando de 47,8 a 54,2 pontos, com os menores valores registrados no centro da cidade e os maiores na região do Cais, próximo ao rio Vermelho.

Figura 7: Carta-imagem do perímetro urbano de Rondonópolis representando a média de temperatura e umidade relativa do ar às $\mathbf{2 1}$ horas.

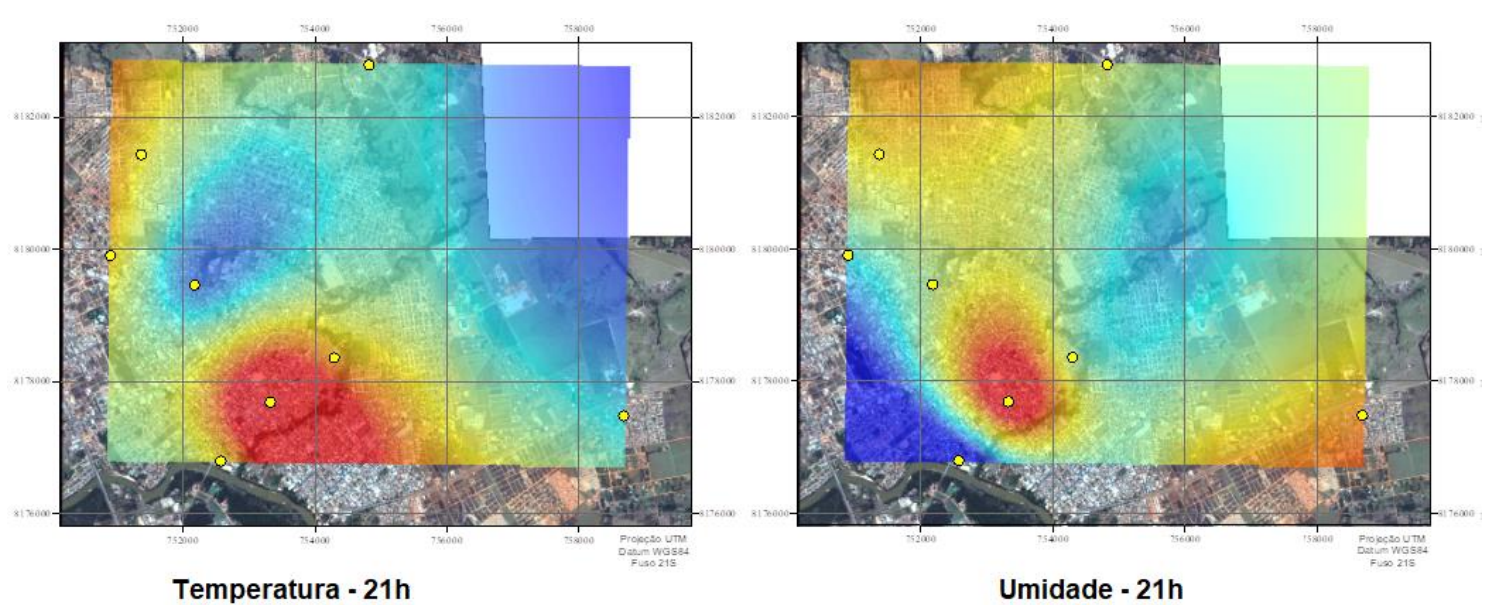

Da análise espacial dos parâmetros considerados nesta pesquisa foi possível constatar que o desconforto térmico, associando altas temperaturas e baixos valores de umidade relativa do ar, é maior no Centro da cidade, onde ocorre maior densidade de construções, menor presença de arborização, alto fluxo de veículos e impermeabilização do solo. 
De modo geral, considerando a amplitude térmica apresentada nos mapas, foi possível observar que nos bairros periféricos foram registradas as menores temperaturas e maiores índices de umidade relativa. A ocorrência das menores temperaturas pode ser explicada, principalmente, pelo fato desses pontos localizarem-se em altitudes mais elevadas comparadas às outras áreas de observação (MINAKI et. al, 2005).

\section{Áreas de preservação permanente}

Como descrito foram delimitadas com o software ArcGIS 9.3.1 a mata ciliar do rio Vermelho, Ribeirão Arareau e os córregos tributários, para diagnóstico das Áreas de Preservação Permanente nesses cursos d'água que cortam o perímetro urbano (Figura 8).

Figura 8: Delimitação da mata ciliar no perímetro urbano de Rondonópolis.

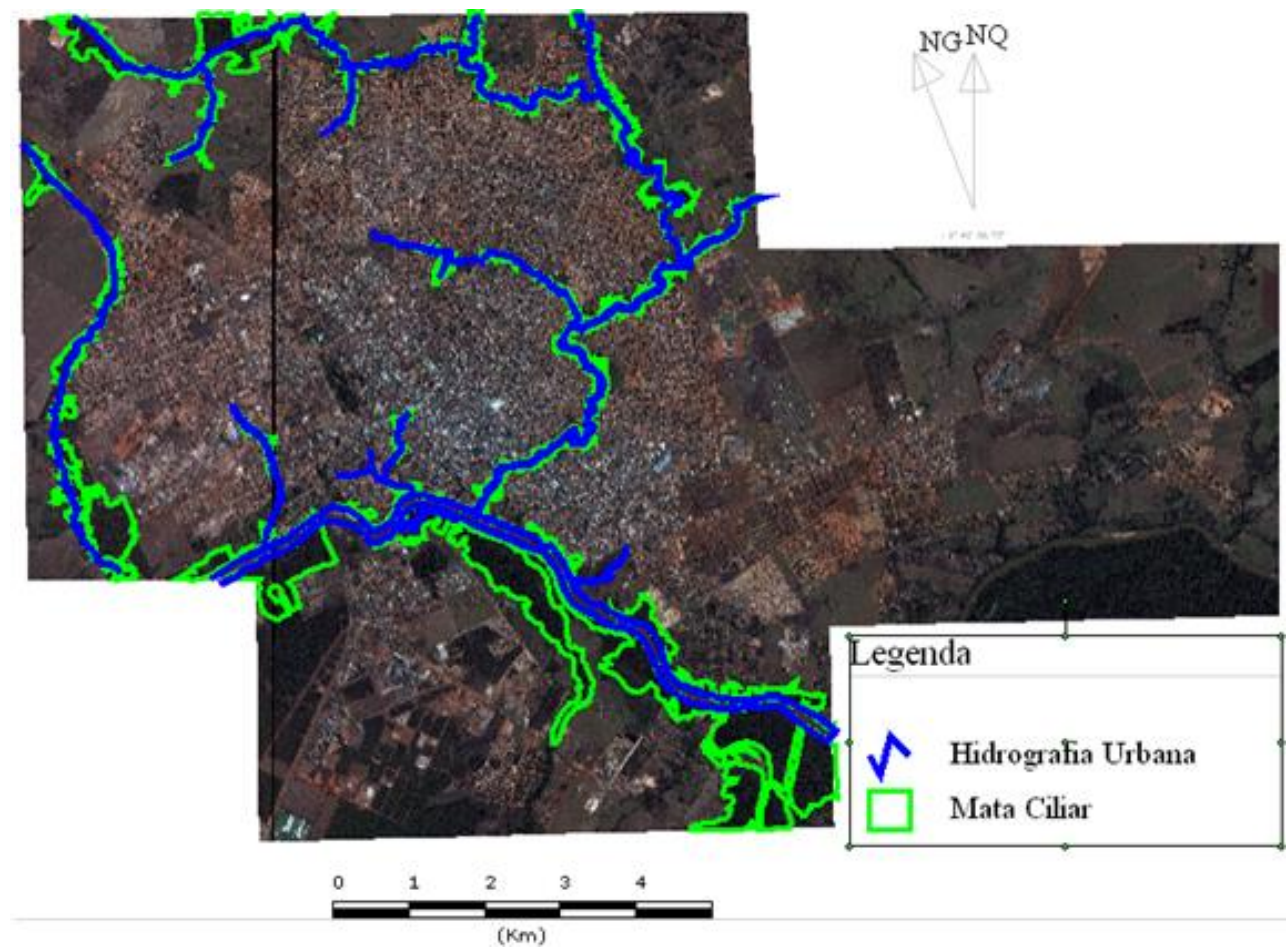

Após a delimitação das APP's na hidrografia urbana da cidade de Rondonópolis fez-se uma análise da ação antrópica a fim de se obter resultados quantitativos nas áreas de preservação permanente.

Analisando a Tabela 01 é possível avaliar a situação da hidrografia do perímetro urbano, na qual é apresentada a largura da APP correspondente à largura de cada curso d'água, de acordo com o Plano Diretor de Rondonópolis. Além disso, é apresentada a área total de preservação permanente correspondente a todos os córregos e rios no perímetro urbano de Rondonópolis. Em seguida é apresentada a área correspondente à situação irregular, verificada pela diferença das APPs pela área delimitada de mata ciliar. Neste sentido, o diagnóstico mostra o percentual de área utilizada de forma irregular nas APPs. 
Tabela 01. Diagnóstico das áreas de preservação permanente no perímetro urbano de Rondonópolis.

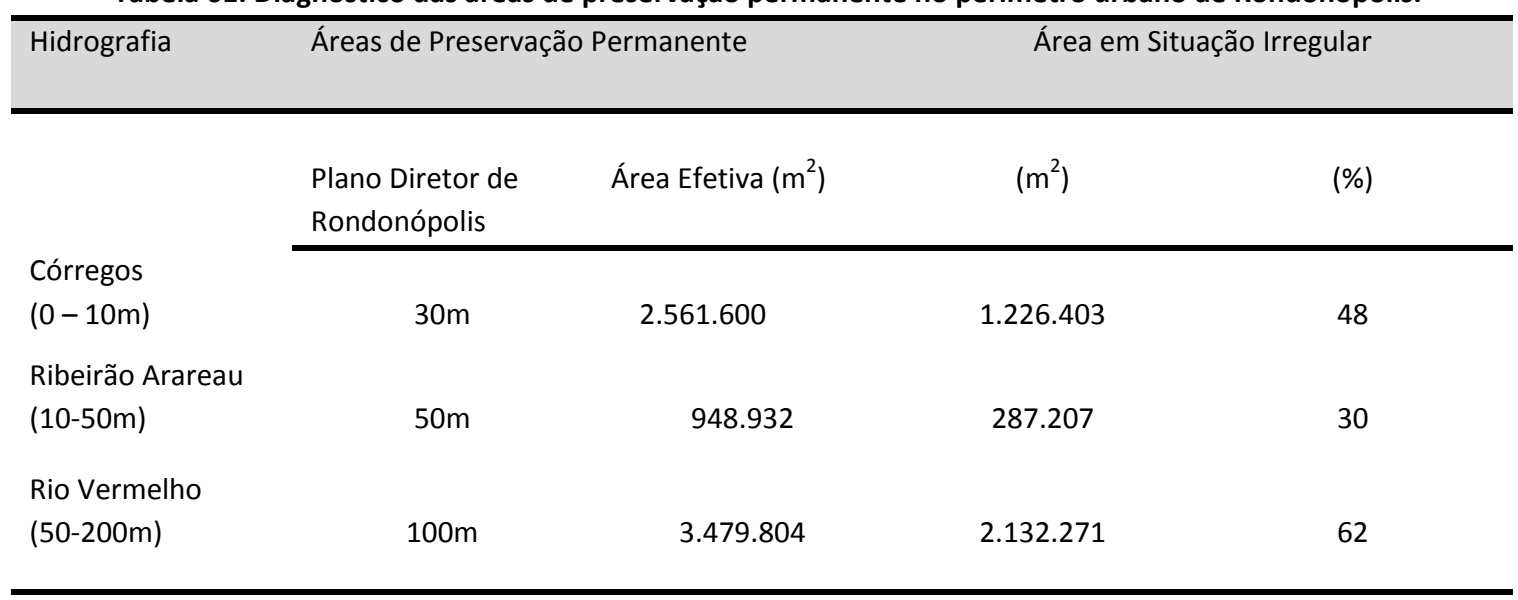

Os córregos tributários que cortam o perímetro urbano apresentam situação irregular de $48 \%$ na APP, ou seja, quase a metade de sua área encontra-se degradada. Já o Ribeirão Arareau registrou uma situação irregular de 30\%, mostrando uma maior preservação da mata ciliar comparado com a situação de seus tributários.

Com relação ao Rio Vermelho, o trecho que atravessa o perímetro urbano apresenta situação irregular de 62\% na APP.

Esses dados obtidos no estudo realizado na hidrografia do perímetro urbano de Rondonópolis contrariam a Lei Ambiental Municipal, pois nenhum dos cursos d'água apresenta situação regular nas APPs em toda sua extensão.

\section{CONCLUSÕES}

O uso da técnica de geoprocessamento foi imprescindível para realizar o diagnóstico da área de estudo, envolvendo ferramentas disponíveis em sistemas de informações geográficas relacionadas neste contexto.

Por meio das observações nos mapas de temperatura e umidade relativa do ar, nos pontos amostrais, pode-se avaliar até que ponto a ocupação do solo, vegetação, densidade de construções e relevo contribui para a variação da temperatura no perímetro urbano e o desconforto térmico, como observado no Centro comercial do município.

Com o levantamento de áreas de preservação permanente no perímetro urbano de Rondonópolis, por geoprocessamento, foi possível constatar expressiva ocorrência de situação irregular devido à ausência de mata ciliar, nas quais se observam áreas construídas, impermeabilizadas com asfalto, ou apresentam solo exposto. Sendo assim, há necessidade de se realizar uma ação de recuperação destas áreas e a preservação da mata ciliar existente. 


\section{REFERÊNCIAS BIBLIOGRÁFICAS}

BARCELLOS, C.; BASTOS, F. C. Geoprocessamento, ambiente e saúde: uma união possível? Caderno de Saúde Pública vol. 12, n.3. Rio de Janeiro, 1996. Disponível em: <http://www.scielo.br/scielo.php?pid=S0102311X1996000300012\&script=sci_arttext.> Acesso em 09 de out., 2011.

FLORÊNCIO, B. A. B.; QUEIROZ, A. T. Diagnóstico Ambiental em Área Urbana: bacia hidrográfica do Córrego Cajubá (Uberlândia/MG), 2011. Faculdade Católica de Uberlândia, 2011. PIBIC. 24 p.

LIMA, G. N. de. Características do Clima Urbano de Nova Andradina. Universidade Estadual Paulista, 2011 Dissertação. 174 p.

LOBODA, C. R.; ANGELIS, B. L. D. Áreas verdes públicas urbanas: Conceitos, usos e funções. Ambiência. Revista do Centro de Ciências Agrárias e Ambientais v. 1 n. 1 Jan/Jun. 2005.

LOMBARDO, M. A. Ilha de Calor nas Metrópoles: O exemplo de São Paulo - São Paulo: HUCITEC, 1985.

MINAKI, C.; AMORIM, M. C. C. T.. Espaços Urbanos e Qualidade Ambiental - Um Enfoque da Paisagem. Revista Formação, $n^{\circ} 14$ v. 1, 67-82 p.

MINAKI, M.; SILVA, S. R.; AMORIM, M. C. de C. Características da temperatura em ambiente urbano. Anais do X Encontro de Geógrafos da América Latina. Universidade de São Paulo, 2005. 13 p.

PROEXT MCIDADES/UFMT. Programa Nacional de Capacitação das Cidades. Universidade Federal de Mato Grosso. Rondonópolis, 2009.

RAUBER, A. C. C.. Diagnóstico ambiental urbano do meio físico de Santa Maria - RS. Universidade Federal de Santa Maria, 2008. Dissertação. 98 p. 